Int. J. Dev. Biol. 59: 79-86 (2015)

doi: $10.1387 / \mathrm{ijdb} .150081 \mathrm{gm}$

\title{
Cell competition, apoptosis and tumour development
}

\author{
GINÉS MORATA* and LUNA BALLESTEROS-ARIAS \\ Centro de Biología Molecular Severo Ochoa, Madrid, Spain
}

\begin{abstract}
The phenomenon of cell competition is an interactive process originally discovered in the imaginal discs of Drosophila; it is a developmental mechanism that identifies and eliminates cells that are weaker than their neighbours or have features that make them different or not well adapted to their surroundings. It appears to be an important homeostatic mechanism to contribute to the general fitness of developing tissues. Here we discuss some of the basic features of cell competition and then focus on results indicating that cell competition is responsible for the removal of malignant or aberrant cells that may appear during development, although in certain circumstances it can revert its role to promote tumour growth. We also consider several recent studies that indicate that cell competition also occurs in vertebrates where it performs similar functions.
\end{abstract}

KEY WORDS: cell competition, tumour development, apoptosis, Drosophila, vertebrates

\section{Definition of cell competition}

Cell competition is a homeostatic mechanism designed by evolution to identify and subsequently eliminate cells that are poorly adapted to their developmental environment and may compromise the overall fitness of animal tissues. It was discovered in the imaginal discs of the fruitfly Drosophila in 1975 (Morata and Ripoll, 1975 ) in experiments aimed to test the cell autonomy of the growth rate of Minute $(M)$ heterozygous flies. The Minute genes (hereto after referred to as $M$ ) encode ribosomal proteins (Lambertsson, 1998, Saeboe-Larssen et al., 1998) and their mutations are lethal homozygous. The heterozygous combinations $(M /+)$ lead to viable flies, except for the bristles, which are shorter and thinner than in wildtype flies (the term Minute alludes to the bristle phenotype). A principal feature of $M /+$ flies is that they develop slowly in comparison with normal flies. The developmental delay is due to the limiting amount of ribosomal proteins, which causes a slowdown in protein synthesis. Most of the delay occurs during the larval period (Brehme, 1939), as would be expected because it is at that period when most of the growth occurs.

The experiments reported in 1975 were designed to test whether the developmental delay of $M /+$ flies was due to a cell autonomous slow division rate of $M /+$ cells in the imaginal discs. The general idea was to generate marked clones of cells with different doses of Minute genes and then to compare their growth rate, measured in terms of the size of clones generated at the same time.

There were two types of experiments: 1) generation of wildtype $\left(M^{+}\right)$clones in heterozygous $M /+$ wing discs. It was expected that the $\mathrm{M}^{+}$clones would be larger than control $M /+$ clones. 2) Generation of
$\mathrm{M} /+$ clones in $\mathrm{M}^{+}$discs. This experiment was complementary to the previous one; the expectation was the $M /+$ clones would be smaller than the control $\mathrm{M}^{+}$clones. As it turned out, these experiments were to have a big impact on Drosophila development. Experiment 1 led to the discovery of compartments, whereas experiment 2 led to cell competition.

Experiment 2 is illustrated in Fig. 1; the slowly dividing clones of $\mathrm{M} /+$ cells were expected to be smaller than control $\mathrm{M}^{+}$clones generated in the same wings. Indeed this was the result found for clones in the abdomen, thus demonstrating the cell autonomy of the retarding $M /+$ condition. But the surprising finding was that in the wing disc those slow-growing clones disappeared after $24 \mathrm{hrs}$, even though $M /+$ cells are perfectly viable (flies of this genotype are viable and fertile). We assumed that, within the constrained space of the imaginal discs, these slow-dividing cells could not compete with their faster-dividing neighbours in capturing nutrients or other factors. So we named this phenomenon as cell competition. Subsequent work (Simpson, 1979, Simpson and Morata, 1981) confirmed the original observation and also emphasized the contextdependent nature of cell competition "It must be emphasized that the Minute cells are only unviable when they are growing next to non-Minute cells. The process of cell competition therefore relies upon cell interaction" (Simpson and Morata, 1981). The results also indicated that the interactions leading to cell competition occur between cells located very close or adjacent (Simpson and Morata, 1981). This idea is strongly supported by recent work in

Abbreviations used in this paper: M, Minute gene.

\footnotetext{
*Address correspondence to: Ginés Morata. Centro de Biología Molecular Severo Ochoa, C/ Nicolás Cabrera, 1. 28049, Madrid, Spain. Tel: 91-196-4696. E-mail: gmorata@cbm.csic.es
}

Accepted: 6 May 2015.

ISSN: Online 1696-3547, Print 0214-6282 
which the interacting cells are visualized in the wing disc ( $\mathrm{Li}$ and Baker, 2007, Martin et al., 2009).

\section{Loser cells are eliminated by apoptosis}

The interactions between the $M /+$ and $M^{+}$cells (hereto after referred to as losers and winners respectively) lead to the disappearance of the loser cells, which are per se viable, suggesting the existence of an intrinsic mechanism to remove them. This is indeed the case (Moreno et al., 2002): between 24-48 hrs after juxtaposing slow-dividing loser and fast-dividing winner cells (that is, after the slow dividing $M /+$ clones were initiated) the loser cells initiate apoptosis. This apoptosis is mediated by the Jun $\mathrm{N}$-terminal kinase (JNK) pathway (see Fig. 2 in Moreno et al., 2002), which is implicated in stress-induced apoptosis in Drosophila (Stronach and Perrimon, 1999). This finding has been confirmed by more recent work (Brumby and Richardson, 2003, Li and Baker, 2007, Martin et al., 2009, Menendez et al., 2010, Tamori et al., 2010), although the involvement of JNK has not been demonstrated in some cases (de la Cova et al., 2004, Rodrigues et al., 2012, Tyler et al., 2007).

The fact that loser cells commonly die by JNK-mediated apoptosis has some interesting implications as it has been shown that JNK activity causes the release of mitogenic signals that affect the growth of the neighbour tissue (Perez-Garijo et al., 2009; Ryoo et al., 2004). As we discuss later this property may be of interest when analysing cell competition in tumour development.

\section{Mechanisms of cell competition}

The molecular mechanisms behind cell competition are not yet known. After a genomic screen designed to discover genes required for cell competition, Rhiner et al., identified flower (fwe), a gene encoding a trans-membrane protein that also appears to be implicated in synaptic vesicle exo- and endocytosis (Yao et al., 2009). fwe generates three RNA forms, a ubiquitous one, fwe $e^{u b i}$, and two others, fwe $e^{\text {Lose } A}$ and fwe ${ }^{\text {Lose } B}$, which are up regulated in loser cells during cell competition (Rhiner et al., 2010). The observation that clones overexpressing fwe $e^{\text {Lose } A}$ and $f w e^{\text {Lose } B}$ tend to be eliminated suggests that the activity of these proteins labels the cells for removal. It also indicates that fwe ${ }^{\operatorname{Lose} A}$ and $f w e^{\text {Lose } B}$ can be taken as marks of cell competition. Still, how fwe $e^{\text {Lose } A}$ and/or fwe ${ }^{\text {Lose B }}$ expression initiates apoptosis is not known.

Very recently, Meyer et al., have reported that loser cells are eliminated through the activation of a novel pathway that incorporates components of the Toll and Imd pathways, responsible for innate immunity in Drosophila (Meyer et al., 2014). Normally Toll and Imd activate genes encoding antimicrobial peptides, aimed to eliminate foreign pathogens like bacteria or fungi; but to eliminate loser cells this novel pathway activates the pro-apoptotic genes reaper and hid. Thus, it appears that loser cells are recognised as non-self by their neighbours. The mechanism involved in the activation of the innate immunity system in the loser cells is an intriguing problem yet to be elucidated.

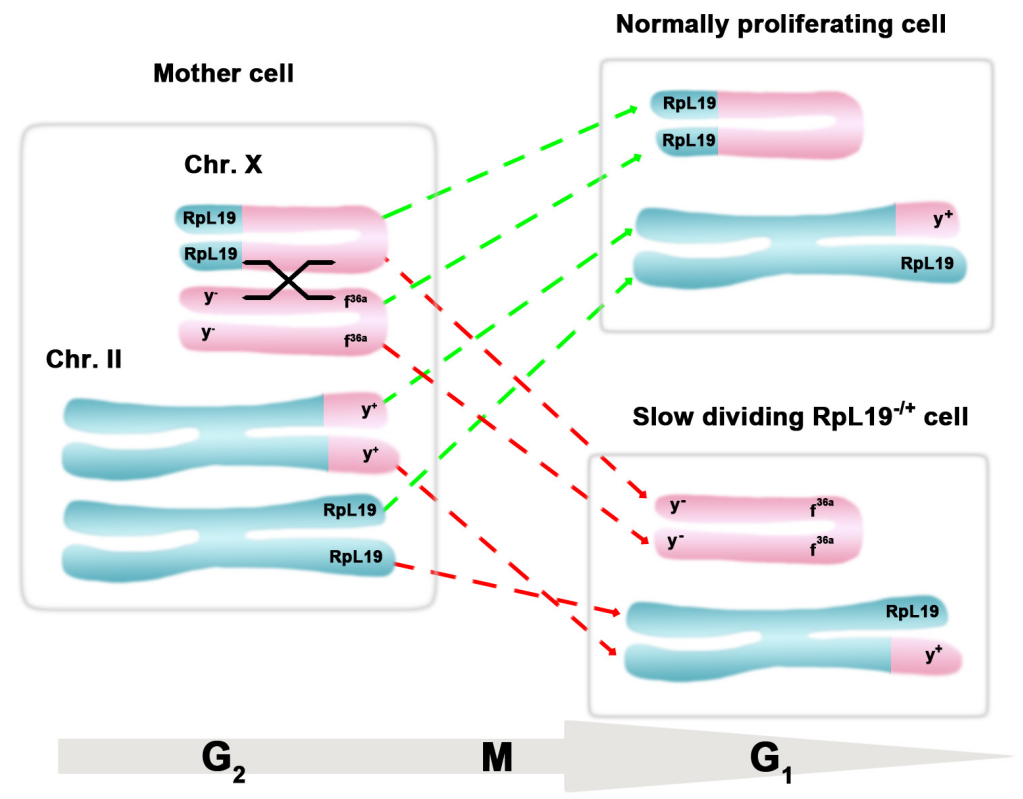

Fig. 1. Generating slow dividing cells. In this diagram we represent one of the genotypes used in the original Minute experiments. Flies of genotype y $\mathrm{f}^{36 a} / \mathrm{T}(1 ; 2)$ $\mathrm{Sc}^{\mathrm{S} 2} /^{+}$were used for this experiment. As shown in the figure (mother cell), in the $\mathrm{T}(1 ; 2) \mathrm{Sc}^{\mathrm{S2}}$ translocation a portion of the // chromosome bearing the RpL19 (Minute) gene (blue) is interchanged with a portion of the tip of the $X$ chromosome carrying the normalyellow gene (pink). The phenotype of these flies is wildtype, and because they contain the normal dose of the RpL19 gene, the growth rate is also normal. $X$-ray induced mitotic recombination in the $X$ chromosome results, after mitosis, in two sister cells: one cell (top) will proliferate normally, as it has three doses of RpL19, but the other cell (bottom, labelled with the marker forked ${ }^{36 a}$ ) contains only one copy of RpL19 and will proliferate slowly in comparison with the sister cell.

\section{The function of cell competition}

The original conclusion that cell competition eliminates relatively weak cells within the epithelium was supported by additional work. Bohni et al., reported a mutation, termed chico, defective in the insulin signalling pathway. chico mutant flies are viable but of small size, about half the wildtype. The observation was that chico mutant clones generated in normal discs are eliminated (Bohni et al., 1999). As in the case of $M /+$ cells, the elimination of chico clones was the result of cell interactions; chico cells are only unviable when placed next to wildtype cells. A similar observation was also made using hypomorphic mutants of dmyc, which are viable as flies but mutant clones do not survive within the context of wildtype cells (Johnston et al., 1999).

An extension of this idea is that cell competition is responsible for the elimination of cells that are not well adapted to a particular developmental context; it would include not only slowly dividing or weaker cells but also those that do not have the identity corresponding to the cell population to which they belong. Adachi-Yamada and O'Connor showed that discontinuities in the Dpp gradient in the imaginal discs generate local apoptosis mediated by the activation of the JNK pathway, suggesting the existence of a mechanism to identify and to remove incorrectly specified cells (Adachi-Yamada and O'Connor, 2002). As pointed out by Adachi-Yamada and O'Connor, this phenomenon, which they call morphogenetic apoptosis, is likely related to cell competition. Not only because the implication of the JNK pathway, but the timing of events is also very similar: in morphogenetic apoptosis, like in 
classical cell competition, apoptosis is triggered in the loser cells between 24-48 hrs after the onset of the cell interactions.

Milan et al., provided a related observation. The gene spalt (sal) is expressed in a region covering the medial part of the wing. Clones of cells overexpressing sal survive in the medial region of the disc where sal is normally expressed, but are eliminated in the lateral regions where sal is not normally active (Milan et al., 2002). The interpretation is that the ectopic sal activity in cells of the lateral region leads them to acquire an incorrect (medial) identity that is recognized as aberrant by the neighbours thus triggering cell competition. Another example (Estella, unpublished) is the behaviour of mutant clones for Distal-less (DII), a gene that is expressed in and specifies distal identity of the leg (Fig. 2A, GFP; Fig. 2B, dashed line). DII - clones in the DII domain are eliminated by apoptosis, while those localised outside the DII domain develop normally (Fig. 2B). It is the identity conflict of the DIl clones in the domain what appears to trigger cell competition.

The general proposition is that cell competition fulfils a general surveillance role to recognise and subsequently eliminate cells with developmental/metabolic features different from those of the same cell population.

\section{Cell competition as a tumour suppressor mechanism in Drosophila}

The idea that cell competition acts as a tumour suppressor mechanism derives from its general surveillance function described above; it recognises tumour cells as aberrant and proceeds to eliminate them. Much of the connection between cell competition and tumour development comes from studies on a group of Drosophila tumour suppressor genes. Some of them (lethal giant larvae (lgl), scribble (scrib) and disc large (dlg)) affect the apico-basal polarity of epithelial cells (Assemat et al., 2008, Tepass et al., 2001), while others like Vps25, Rab5or avalanche are components of the endosomal trafficking machinery (Shivas et al., 2010).

We will focus on Igl and Rab5 but the conclusions can also be applied to the other oncogenic mutations. It was reported long ago (Gateff, 1978) that mutant /g/larvae survive a long time and reach very big size (hence the name) before dying. These larvae develop massive tumours, especially in the brain and in the imaginal discs, indicating that $l g /$ mutant cells are viable and able to proliferate. A feature of $\mathrm{lg} /$ mutant cells worth emphasizing is that they can continue dividing as long as the larva is alive (Menendez et al.,
2010); contrary to normal discs or compartments, those composed of $l g l$ (or Rab5) mutant cells do not generate the intrinsic signal(s) that stop growth once they have achieved the final size. This ability to proliferate indefinitely, although their proliferation rate is not higher than that of normal cells (Menendez et al., 2010), is a distinctive tumour feature.

Anumber of experiments have assayed the tumorigenic potential of Igl, scrib and Rab5 mutant clones (Ballesteros-Arias et al., 2014, Brumby and Richardson, 2003, Menendez et al., 2010; Tamori et al., 2010). These experiments amount to planting tumour cells within a population of non-tumour cells, a situation that mimics the usual way in which tumours appear in animals. The common observation was that in spite of the growth potential of the mutant discs or compartments, clones of $/ g l$, scribor Rab5mutant cells are normally eliminated (Fig. $3 \mathrm{~A}$ ), indicating that their elimination is the result of interactions with their non-mutant neighbours (BallesterosArias et al., 2014, Chen et al., 2012, Grzeschik et al., 2010, Igaki et al., 2009, Menendez et al., 2010, Tamori et al., 2010). These clones only survive 48-72 hrs after they are generated and are eliminated by JNK-mediated apoptosis (Fig. 3B). Furthermore, the $\mathrm{lg} /$ cells in apoptosis appear systematically at the clone borders, the place where the mutant and non-mutant cells are juxtaposed (Ballesteros-Arias et al., 2014, Menendez et al., 2010, Tamori et al., 2010). All these features are typical of cell competition and resemble the behaviour of juxtaposed $M /+$ and $M^{+}$cells in conventional cell competition experiments (Moreno et al., 2002).

Similar experiments have been reported recently for scrib and dlg mutant cells. Igaki et al., found that scrib and dlg mutant clones are eliminated when surrounded by non-mutant cells, again by JNK mediated apoptosis (Igaki et al., 2009). In addition, they show that it is an autocrine process in which the ligand Eiger (the Drosophila homologue of the mammalian Tumour Necrosis Factor) translocates to the endosomes and initiates JNK signalling in the scrib mutant cells. Igaki et al., interpret these results as suggestive of the existence of an intrinsic tumour suppressor mechanism to remove oncogenic cells defective in cell polarity. It is of interest that the initiation of the autocrine process of self-removal of scrib cells is triggered by the interaction with non-mutant cells, thus emphasizing the role of the cell interactions. The involvement of cell competition in the process is further supported by the observation that molecular markers of cell competition such as the fwe $e^{\text {lose }}$ isoforms are expressed in scrib mutant clones (Rhiner et al., 2010).

In conclusion, as part of its general surveillance function, cell
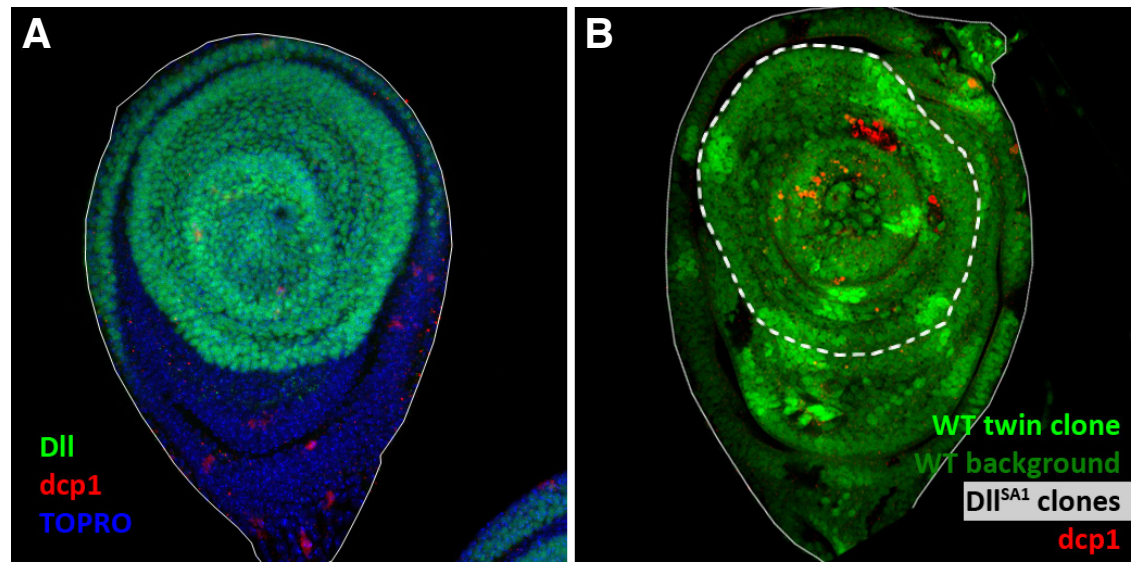

Fig. 2. Cell competition eliminates cells with the inappropriate identity according to position. Distalless (DII) is a gene expressed in the distal domains of the leg imaginal discs (GFP), and confers cells distal identity (A). (B) DIISA1 mutant clones (lack of GFP) are shown in a leg disc. These clones behave differently depending on the developmental context in which they are growing. Those outside the DII domain (outside the dashed line) are viable and develop normally. Those growing in the DIl domain (within the dashed line) are eliminated after 48-72 hours of clone induction. They die by apoptosis, as indicated by dcp 1 (active Caspase) staining. Also, in many occasions, only the wild type 2xGFP twin clones generated at the same time as the mutant ones can be observed, indicating that there were mutant clones that have disappeared by cell competition. Image in panel (B) from Carlos Estella. 

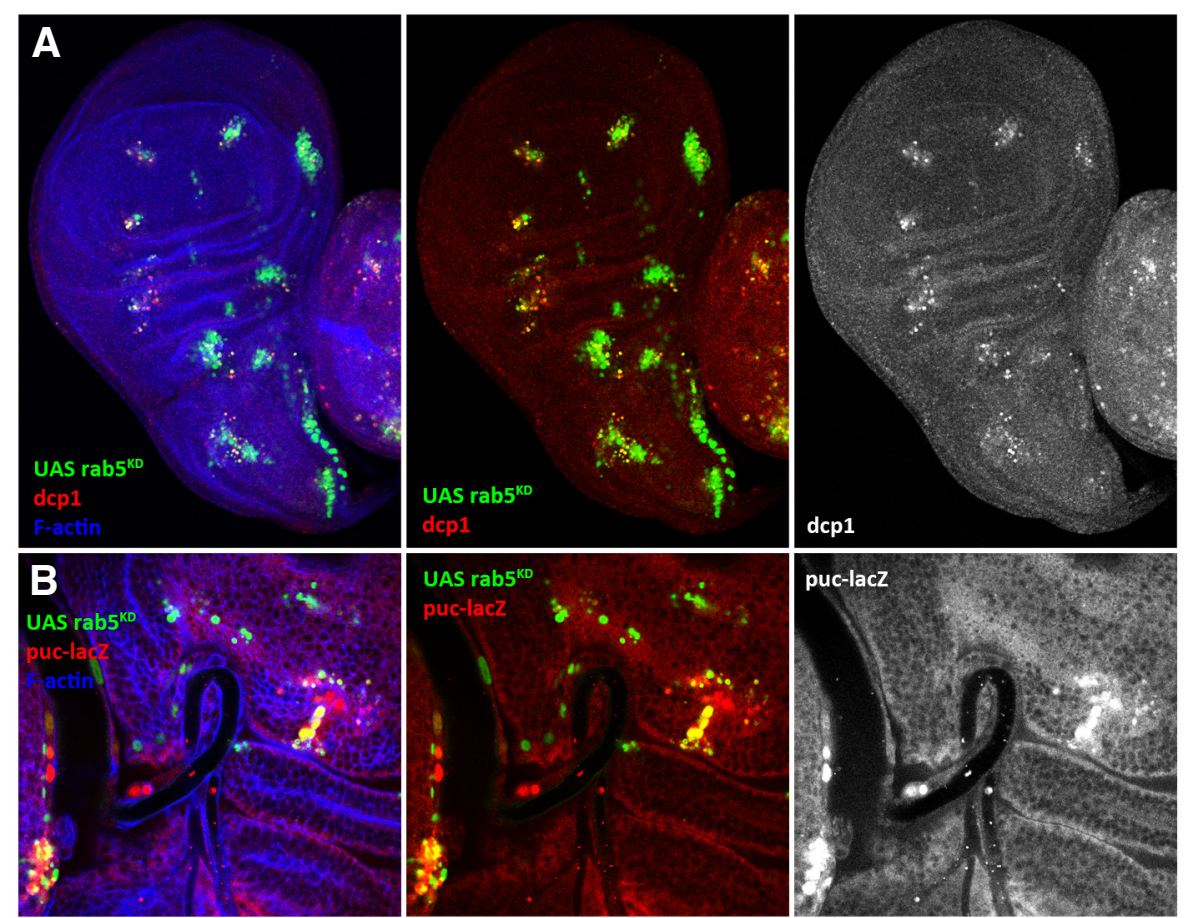

Fig. 3. Cell competition eliminates oncogenic cells by activating the JNK apoptotic signalling pathway. (A) Several clones, labelled with GFP, defective for Rab5, a tumour suppressor gene. The dcp 1 label in the clones indicates they are being actively eliminated from the disc. (B) Some Rab5 clones with JNK activity, as pointed out by the expression of the puckered (puc-lacZ) downstream target. The clones in both cases were induced $72 \mathrm{~h}$ before fixation and staining.

competition is responsible for the elimination of potentially oncogenic cells. In normal circumstances the interaction between tumour/nontumour cells favours the non-tumour ones and therefore tumour formation is prevented.

\section{Tumour cells may evade cell competition by forming a protective microenvironment}

The fact that it is possible to generate tumours by inducing $|g|$ and scrib mutant clones in the discs indicates that the surveillance role of cell competition can sometimes be evaded. The bestdocumented cases involve the overexpression of the Ras pathway in $\mathrm{g} / \mathrm{lor}$ scrib mutant cells. It makes use of the Ras ${ }^{V 12}$ transgene, which causes constitutive activity of the pathway (Barbacid, 1987). The observation is that frequently $\mathrm{Igl} \operatorname{Ras}^{V 12}$ or scrib Ras ${ }^{V 12}$ clones are not eliminated and can develop overgrowing tumours that colonise the entire disc.

One critical feature of $I g l \operatorname{Ras}^{V 12}$ clones, and one reason of their overgrowth, is that their cells have a high proliferation rate, caused by down regulation of the Hippo pathway (Grzeschik et al., 2010), although the mechanism behind this is not known. The idea of linking proliferation rate with the survival of the clones is supported by the observation that mimicking Hippo down regulation in Igl mutant cells, using UAS-Yki (Huang et al., 2005), promotes the survival of the clones and promotes tumorigenesis. Since a classical feature of cell competition is the interaction of slow and fast dividing cells, a simple interpretation of these results is that, having acquired a higher proliferation rate, Iglor scrib mutant cells have now become "supercompetitors" and eliminate the non-tumour cells. This would be a reversion of the normal process and now cell competition behaves as a tumour promoting mechanism. This possibility has been emphasized in some reviews (Amoyel and Bach, 2014, Rhiner and Moreno, 2009).

However, a careful study of the tumorigenic potential of fast growing $\mathrm{IgI} \mathrm{Ras}^{\mathrm{V} 12}$ scrib Ras $^{\mathrm{V12}}$ and $I g I U A S-Y k i$ clones indicated an unforeseen complexity (Menendez et al., 2010). A key factor to develop an invasive tumour appears to be the density of clones in the disc. A standard experiment involving FRT/FLP mediated recombination generates a large number of clones, which we estimate cover about $12 \%$ of the entire disc. That is, under those conditions a substantial portion of the tissue becomes mutant. Moreover, because of their large number and high proliferation rate, these clones often merge and form a big mass of mutant tissue (Fig. 4C). In this kind of experiment it is very difficult to follow the fate of individual clones and to examine their oncogenic potential.

An experiment designed to induce few (about 2) clones per disc revealed that the great majority of the Igl Ras ${ }^{V 12}$, scrib $\operatorname{Ras}^{V 12}$ or Igl UAS-Yki clones fail to generate a tumour: less than $10 \%$ of the discs become tumorous (Menendez et al., 2010). Moreover, many of the clones are either eliminated or grow very poorly as many of their cells die by apoptosis. A similar observation has been made recently for Rab5 Ras $^{V 12}$ clones (Ballesteros-Arias et al., 2014). The mechanism of cell elimination is the same as in the Igl or scrib mutant cells, involving the activation of the apoptotic JNK pathway.

The conclusion from these experiments is that even though Igl Ras ${ }^{V 12}$, scrib Ras ${ }^{V 12}$, Igl UAS-Yki or Rab5 Ras ${ }^{V 12}$ cells possess proliferation advantage with respect to surrounding non-tumour ones, they are frequently recognised as aberrant and eliminated. This indicates that cell competition is a powerful mechanism able to eliminate cells even if they have a high division rate. Menendez et al., proposed that in order to develop into a tumour, $\operatorname{lgl} \operatorname{Ras}^{V 12}$ (or scrib $\operatorname{Ras}^{\mathrm{V12}}$ ) cells would have to form a protective microenvironment so that at least some cells evade cell competition (Menendez et al., 2010). This event could result from the merging of several clones into a mass of tumour cells. Cell competition would still act on those tumours, but being a short-range mechanism, it eliminates cells preferentially at the periphery; the cells inside are out of cell competition range and can continue proliferating (Fig. 4). Because tumour cells are capable of proliferating indefinitely, they form a tumour that will grow as long as the larva is alive. The scheme of Fig. $4 \mathrm{C}$ illustrates this view.

We have recently reported strong evidence supporting the microenvironment hypothesis (Ballesteros-Arias et al., 2014). The experiments made use of the oncogenic transformation caused by endocytosis defective Rab5 mutations; individual mutant Rab5 clones surrounded by normal cells were eliminated by cell competition, just like $\mathrm{g} / \mathrm{l}$ or scrib mutant clones. However, if a group of about 400-500 cells, also surrounded by normal cells, are 
simultaneously made defective in Rab5 activity they survive and form an invasive tumour. It is worth emphasizing that these Rab5 defective cells do not have proliferation advantage provided by the $\operatorname{Ras}^{V 12}$ transgene, they simply continue proliferating while the rest of the disc arrests growth.

\section{Cell competition as a tumorigenic stimulus: supercom- petition or mitogenic signalling from loser cells?}

Cell competition is a homeostatic mechanism that detects and eliminates cells that would compromise the development/ function of an organ or an epithelium. However, several studies have described cell competition interactions in which the loser cell is not aberrant or has the wrong identity, but it is wild type (de la Cova et al., 2004, Moreno and Basler, 2004, Rodrigues et al., 2012, Tyler et al., 2007, Ziosi et al., 2010). This phenomenon has been named supercompetition (Moreno and Basler, 2004). It has been described for the interaction between cells possessing high proliferation rate because they contain extra copies of dMyc and cells that have normal amounts of $\mathrm{dMyc}$, with lower division rate. In this case, it is the wildtype cells that are the losers. The implication of this idea is that cells with high dMyc activity would grow at the expense of wildtype tissue, indicating that cell competition would be favouring cells with high dMyc activity, a characteristic feature of many tumour cells (Gabay et al., 2014).

However, some cases have been described in which cell competition happens independently of dMyc levels (Rodrigues et al., 2012, Vincent et al., 2011), indicating that the outcome of cell competition (i.e. which cell will die upon an interaction) is more complex than a simple comparison of dMyc levels among
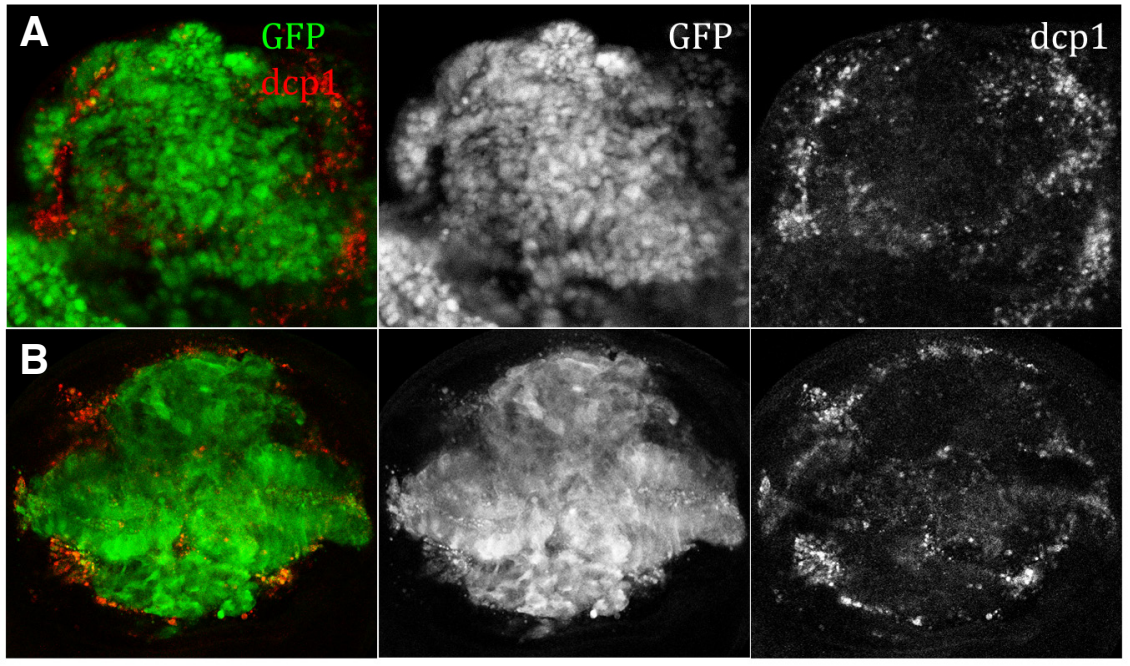

C

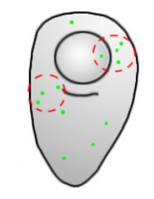

$2^{\text {nd }}$ larval stage

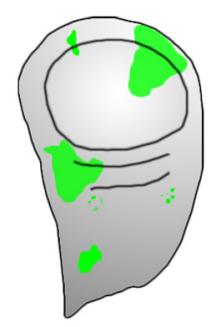

early $3^{\text {rd }}$ larval stage

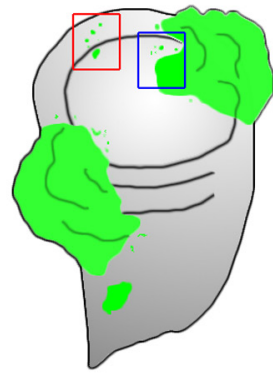

late $3^{\text {rd }}$ larval stage

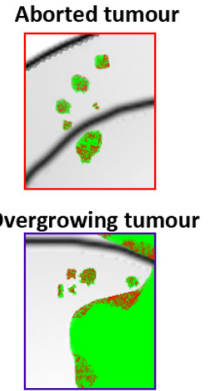

the interacting cells. In support of this view is the work mentioned above about the tumorigenic potential of mutations at the tumour suppressor genes. For example, isolated $l g l \operatorname{Ras}^{V 12}$ clones are out competed although they have dMyc levels higher than surrounding cells (Menendez et al., 2010). Even when Igl Ras ${ }^{V 12}$ clones merge to form a protective microenvironment that allows overgrowth (see Fig. 3 in (Menendez et al., 2010)), there is still elimination of tumour cells at the periphery. Taken together these results argue against the supercompetition mechanism being the mechanism behind tumorigenesis.

We believe that the tumorigenic potential of cell competition is a side effect of the mechanism of cell removal by apoptosis (Fig. 5). It has been found that cells that enter the apoptotic program not only activate the caspases for self-destruction; they also secrete mitogenic signals that induce proliferation of neighbouring cells (Perez-Garijo et al., 2004; Pérez-Garijo et al., 2009; Ryoo et al., 2004). In normal circumstances in which few cells are eliminated, this proliferative signalling does not have much effect. However, in cases of large-scale cell competition, the amount of proliferative signalling emanating from apoptotic cells may be sufficient to stimulate the growth of the tissue close to the tumour or of the tumour cells outside the range of cell competition. Clear example of this situation are the tumours mentioned above in the spalt region (Ballesteros-Arias et al., 2014) in which simultaneous transformation of the entire domain allows survival and overgrowth of the tumour. In these tumours there is an intense band of apoptosis in the borders, generated by cell competition, which occurs precisely at the interface between normal and Rab5 cells. This area is highly proliferative, as indicated by BrdU incorporation, and the cells in division are often very close to those in apoptosis (Fig. 5A and see Fig. 2 in (Ballesteros-Arias et al., 2014)). Possibly as a consequence of the growth signal(s) emanating from the dying cells, those surrounding them acquire high dMyc levels (Fig. $5 \mathrm{~B}, \mathrm{C}$ ). This suggests that the proliferative signalling from apoptotic cells may contribute to the growth of the tumour; the finding that the suppression of apoptosis in the sal domain (making

Fig. 4. Tumour cells can successfully confront cell competition by creating a protective microenvironment. (A) A large Rab5 Ras ${ }^{\mathrm{V} 12}$ patch (labelled with GFP), probably generated by the merging of several independent clones. Note that many cells in the periphery are dying, as indicated by the dcp1 staining (red). (B) An overgrowth of the spalt domain (GFP) caused by the expression of Rab5 ${ }^{\mathrm{D}}$, also showing tumour cells dying at the periphery (red). (C) The evolution of events in a disc containing numerous clones mutant for a tumour suppressor gene, induced at the second larval stage and surrounded by non-tumour cells. All the mutant clones are recognised as losers and the majority are eventually eliminated during the development of the disc (red square). However, as in (A), there are some clones that because of their physical proximity (dashed red circles) can merge to form a large patch. In these overgrowing patches the tumour cells at the periphery are eliminated (labelled red in the blue square) upon the interaction with non-tumour cells. The cells inside the tumour are beyond the reach of cell competition and can continue proliferating. 
it mutant for dronc) inhibits the overgrowth of the tumour strongly supports this view (Ballesteros-Arias et al., 2014). Thus, under these circumstances cell competition reverses its normal antitumour role and stimulates growth through proliferative signalling from apoptotic cells.

\section{Cell competition in vertebrates}

There is accumulating evidence that cell competition is not a specialty of Drosophila but may be a universal mechanism in the Animal Kingdom. Sometime ago, Oliver et al., identified a mouse gene, Belly spot and tail (Bst) that encodes the ribosomal protein RpL24 and that behaves very much like the Drosophila Minute genes; cells carrying only one dose of Bstare viable, but eliminated if in the same population with cells carrying two doses of the gene (Oliver et al., 2004). Furthermore, in a study of rat liver repopulation by transplanted fetal liver stem/progenitor cells, the latter were able to repopulate a disproportionate part of the liver mass due to the elimination by apoptosis of the host hepatocytes adjacent to the transplanted cells (Oertel et al., 2006). The authors propose that cell competition may serve as a strategy for tissue reconstitution after metabolic and other disorders.

More recently, two studies (Claveria et al., 2013, Sancho et al., 2013) have shown that cell competition has a functional role during early mouse development. At the epiblast stage there is endogenous cell competition so that cells with lower levels of Myc are eliminated (Claveria et al., 2013). As very likely Myc levels reflect metabolic activity of the cells, these observations suggest that cell competition plays a role in normal development contributing to select the fitter cells within the epiblast cell pool.

As in Drosophila, cell competition in vertebrates also appears to have a therapeutic role in eliminating oncogenic cells. Norman et al., examined in cell cultures the interactions between normal epithelial cells with others in which the mammalian homolog of the Drosophila scribble gene is inactivated by RNA interference (Norman et al., 2012). The scribble defective cells underwent apoptosis when surrounded by normal cells, but not when they were cultured alone. The conclusion was that it is the close interaction between normal and oncogenic cells what causes the elimination of the latter. This was the first demonstration that an oncogenic transformation may trigger cell competition in mammalian cells.

In a very recent report, Martins et al., have shown that cell competition functions in vivo in the mouse thymus where it has an important anti-tumour role (Martins et al., 2014). The thymus is the organ where the mature T cells are formed and its normal function depends on continuous supply of progenitor cells from the bone marrow. The newcomer progenitors appear to compete successfully for limiting amounts of Interleukin-7, what eventually results in the death of resident progenitors. Preventing the incorporation of fresh progenitors from the bone marrow causes self-renewal of resident progenitor cells and eventually the appearance of a T-cells acute lymphoblastic leukemia that closely resembles the human disease.

Finally, there is also the possibility that cell competition may have a tumour-stimulating role in mammalian tissues. There is evidence (Huang et al., 2011) that mammalian apoptotic cells release the growth factor Prostaglandin E $\left(\mathrm{PGE}_{2}\right)$ just like Drosophila apoptotic cells secrete $\mathrm{Wg}$ and Dpp. It may stimulate the growth of surrounding tissues. Indeed, the proliferation of rat tumour cells is greatly enhanced by the presence in the population of tumour cells that have been lethally irradiated, and the proliferation stimulus is dependent on $\mathrm{PGE}_{2}$. This is a case in which apoptosis has a tumour promoting role. Since cell competition is essentially an apoptosis-based phenomenon, there is the possibility that in some instances the establishment of cell competition in a damaged tissue may lead to tumour growth. In humans, it is known that chronic ulcers caused by persistent infections of Helicobacter pylory are associated with gastric carcinoma (Parsonnet et al., 1991). One may speculate that the cellular stress generated under these (or similar) conditions may result in elevated levels of cell competition/ apoptosis that in turn may lead to tissue hyperproliferation.

\section{A general surveillance mechanism}

Multicellular animals contain a large number of cells, ranging from $10^{3}$ in the nematode worm C. elegans to $10^{6}$ in Drosophila to $4 \mathrm{x} 10^{13}$ in humans to considerable more in bigger animals. The number of genes is well over 15000 and the mutation rate of somatic cells varies greatly but can be roughly estimated in the range of $10^{-6}-10^{-8}$ per cell/per division (Araten et al., 2005). It is clear from those data that during the development of all animal tissues there appear numerous mutant cells that in many instances would be defective in critical metabolic and functional features. This kind of calculation argues for the existence of some tissue intrinsic mechanism responsible for the elimination of cells that acquire undesirable features that may affect the general fitness of the tissue or its normal development. In the case of Cancer, recent estimates (Stratton et al., 2009) indicate that there are at least 350 human genes associated with somatic mutations leading
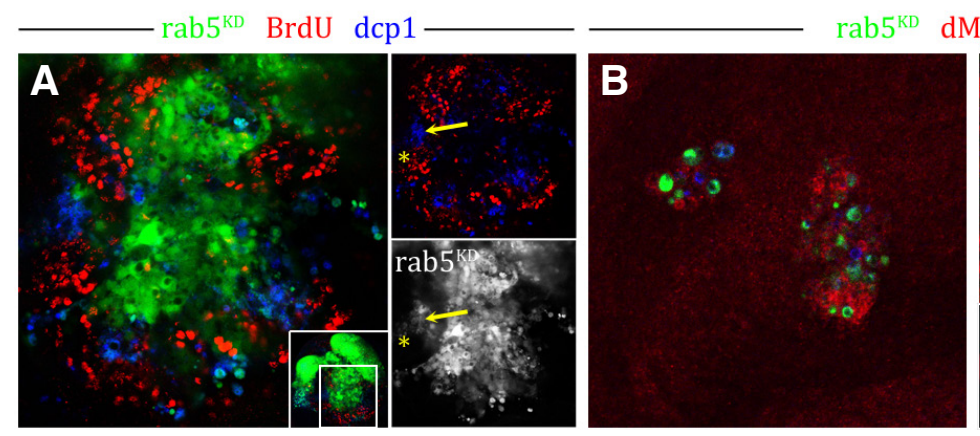

dMyc dcp1

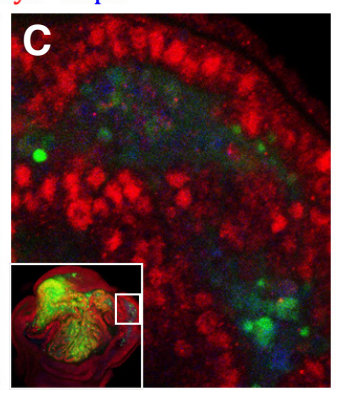

Fig. 5. Dying cells at the periphery of the tumours induce proliferation and subsequent gain of dMyc in neighbouring cells. (A) A magnification of a region of a GFP-marked sal domain deficient for Rab5 (see inset). As described, Rab5 ${ }^{\mathrm{KD}}$ cells at the borders of the tumour are eliminated by apoptosis (dcp1 activity in blue, arrow). Surrounding wildtype cells exhibit high proliferation rate as indicated by BrdU incorporation (red and asterisk). $(\mathbf{B}, \mathbf{C})$ The cells surrounding the loser cells increase their metabolism, as seen by the increase in dMyc protein. The image showed in (B) corresponds to two GFP-marked Rab5 ${ }^{\mathrm{KD}}$ clones, whereas that in (C) is a magnification of a portion of an overgrowing Rab5 ${ }^{\mathrm{KD}}$ sal domain (inset). 
to cancer. For the same argument we make above, considering the number of cells of an individual and the average spontaneous mutation rate for cancer genes, the conclusion is that multicellular animals possibly contain thousands of cancer cells in any moment of their lives. Normally, tumours derive from individual oncogenic cells, which are surrounded by normal cells, a typical scenario for cell competition, and a scenario that must be a common occurrence. The fact that on average cancer arises less than once in a lifetime suggests the existence of powerful tumour suppressing mechanisms in metazoans. We believe that within the general surveillance function of cell competition, the removal of potentially oncogenic cells is one of the tasks.

\section{Acknowledgements}

We wish to thank our colleague Dr. Carlos Estella for providing us with the original photographs for Fig. 2.

\section{References}

ADACHI-YAMADA, T. and O'CONNOR, M.B. (2002). Morphogenetic apoptosis: a mechanism for correcting discontinuities in morphogen gradients. Dev Biol 251: 74-90.

AMOYEL, M. and BACH, E.A. (2014). Cell competition: how to eliminate your neighbours. Development 141: 988-1000.

ARATEN, D.J., GOLDE, D.W., ZHANG, R.H., THALER, H.T., GARGIULO, L., NOTARO, R. and LUZZATTO, L. (2005). A quantitative measurement of the human somatic mutation rate. Cancer Res 65: 8111-8117.

ASSEMAT, E., BAZELLIERES, E., PALLESI-POCACHARD, E., LE BIVIC, A. and MASSEY-HARROCHE, D. (2008). Polarity complex proteins. Biochim Biophys Acta 1778: 614-630.

BALLESTEROS-ARIAS, L., SAAVEDRA, V. and MORATA, G. (2014). Cell competition may function either as tumour-suppressing or as tumour-stimulating factor in Drosophila. Oncogene 33: 4377-84.

BARBACID, M. (1987). ras genes. Annu Rev Biochem 56: 779-827.

BOHNI, R., RIESGO-ESCOVAR, J., OLDHAM, S., BROGIOLO, W., STOCKER, H., ANDRUSS, B.F., BECKINGHAM, K. and HAFEN, E. (1999). Autonomous control of cell and organ size by CHICO, a Drosophila homolog of vertebrate IRS1-4. Cell 97: 865-875.

BREHME, K.S. (1939). A Study of the Effect on Development of "Minute" Mutations in Drosophila melanogaster. Genetics 24: 131-161.

BRUMBY, A.M. and RICHARDSON, H.E. (2003). scribble mutants cooperate with oncogenic Ras or Notch to cause neoplastic overgrowth in Drosophila. EMBO J 22: 5769-5779.

CHEN, C.L., SCHROEDER, M.C., KANGO-SINGH, M., TAO, C. and HALDER, G. (2012). Tumor suppression by cell competition through regulation of the Hippo pathway. Proc. Natl. Acad. Sci. USA 109: 484-489.

CHERA, S., GHILA, L., DOBRETZ, K., WENGER, Y., BAUER, C., BUZGARIU, W., MARTINOU, J.C. and GALLIOT, B. (2009). Apoptotic cells provide an unexpected source of Wnt3 signaling to drive hydra head regeneration. Dev Cell 17: 279-289.

CLAVERIA, C., GIOVINAZZO, G., SIERRA, R. and TORRES, M. (2013). Myc-driven endogenous cell competition in the early mammalian embryo. Nature 500: 39-44.

DE LA COVA, C., ABRIL, M., BELLOSTA, P., GALLANT, P. and JOHNSTON, L.A. (2004). Drosophila myc regulates organ size by inducing cell competition. Cell 117: 107-116.

FAN, Y. and BERGMANN, A. (2008). Distinct mechanisms of apoptosis-induced compensatory proliferation in proliferating and differentiating tissues in the Drosophila eye. Dev Cell 14: 399-410.

GABAY, M., LI, Y. and FELSHER, D.W. (2014). MYC activation is a hallmark of cancer initiation and maintenance. Cold Spring Harb Perspect Med 4.

GATEFF, E. (1978). Malignant neoplasms of genetic origin in Drosophila melanogaster. Science 200: 1448-1459.

GRZESCHIK, N.A., PARSONS, L.M. and RICHARDSON, H.E. (2010). Lgl, the SWH pathway and tumorigenesis: It's a matter of context \& competition! Cell Cycle 9:
3202-3212.

HUANG, J., WU, S., BARRERA, J., MATTHEWS, K. and PAN, D. (2005). The Hippo signaling pathway coordinately regulates cell proliferation and apoptosis by inactivating Yorkie, the Drosophila Homolog of YAP. Cell 122: 421-434.

HUANG, Q., LI, F., LIU, X., LI, W., SHI, W., LIU, F.F., O'SULLIVAN, B., HE, Z., PENG, Y., TAN, A.C. et al., (2011). Caspase 3-mediated stimulation of tumor cell repopulation during cancer radiotherapy. Nat Med 17: 860-866.

HUH, J.R., GUO, M. and HAY, B.A. (2004). Compensatory proliferation induced by cell death in the Drosophila wing disc requires activity of the apical cell death caspase Dronc in a nonapoptotic role. Curr Biol 14: 1262-1266.

IGAKI, T., PASTOR-PAREJA, J.C., AONUMA, H., MIURA, M. and XU, T. (2009). Intrinsic tumor suppression and epithelial maintenance by endocytic activation of Eiger/TNF signaling in Drosophila. Dev Cell 16: 458-465.

JOHNSTON, L.A., PROBER, D.A., EDGAR, B.A., EISENMAN, R.N. and GALLANT, P. (1999). Drosophila myc regulates cellular growth during development. Cell 98: $779-790$.

LAMBERTSSON, A. (1998). The minute genes in Drosophila and their molecular functions. Adv Genet 38: 69-134.

LI, F., HUANG, Q., CHEN, J., PENG, Y., ROOP, D.R., BEDFORD, J.S. and LI, C.Y. (2010). Apoptotic cells activate the "phoenix rising" pathway to promote wound healing and tissue regeneration. Sci Signal 3: ra13.

LI, W. and BAKER, N.E. (2007). Engulfment is required for cell competition. Cell 129: $1215-1225$.

MARTIN, F.A., HERRERA, S.C. and MORATA, G. (2009). Cell competition, growth and size control in the Drosophila wing imaginal disc. Development 136: 3747-3756.

MARTINS, V.C., BUSCH, K., JURAEVA, D., BLUM, C., LUDWIG, C., RASCHE, V., LASITSCHKA, F., MASTITSKY, S.E., BRORS, B., HIELSCHER, T. et al., (2014). Cell competition is a tumour suppressor mechanism in the thymus. Nature 509 : 465-470.

MENENDEZ, J., PEREZ-GARIJO, A., CALlEJA, M. and MORATA, G. (2010). A tumor-suppressing mechanism in Drosophila involving cell competition and the Hippo pathway. Proc. Natl. Acad. Sci. USA 107: 14651-14656.

MEYER, S.N., AMOYEL, M., BERGANTINOS, C., DE LA COVA, C., SCHERTEL, C., BASLER, K. and JOHNSTON, L.A. (2014). An ancient defense system eliminates unfit cells from developing tissues during cell competition. Science 346: 1258236.

MILAN, M., PEREZ, L. and COHEN, S.M. (2002). Short-range cell interactions and cell survival in the Drosophila wing. Dev Cell 2: 797-805.

MORATA, G. and RIPOLL, P. (1975). Minutes: mutants of Drosophila autonomously affecting cell division rate. Dev Biol 42: 211-221.

MORENO, E. and BASLER, K. (2004). dMyc transforms cells into super-competitors. Cell 117: 117-129.

MORENO, E., BASLER, K. and MORATA, G. (2002). Cells compete for decapentaplegic survival factor to prevent apoptosis in Drosophila wing development. Nature 416: 755-759.

NORMAN, M., WISNIEWSKA, K.A., LAWRENSON, K., GARCIA-MIRANDA, P., TADA, M., KAJITA, M., MANO, H., ISHIKAWA, S., IKEGAWA, M., SHIMADA, T. et al., (2012). Loss of Scribble causes cell competition in mammalian cells. J Cell Sci 125: 59-66.

OERTEL, M., MENTHENA, A., DABEVA, M.D. and SHAFRITZ, D.A. (2006). Cell competition leads to a high level of normal liver reconstitution by transplanted fetal liver stem/progenitor cells. Gastroenterology 130: 507-520; quiz 590.

OLIVER, E.R., SAUNDERS, T.L., TARLE, S.A. and GLASER, T. (2004). Ribosomal protein L24 defect in belly spot and tail (Bst), a mouse Minute. Development 131: 3907-3920.

PARSONNET, J., FRIEDMAN, G.D., VANDERSTEEN, D.P., CHANG, Y., VOGELMAN J.H., ORENTREICH, N. and SIBLEY, R.K. (1991). Helicobacter pylori infection and the risk of gastric carcinoma. N Engl J Med 325: 1127-1131.

PEREZ-GARIJO, A., MARTIN, F.A. and MORATA, G. (2004). Caspase inhibition during apoptosis causes abnormal signalling and developmental aberrations in Drosophila. Development 131: 5591-5598.

PÉREZ-GARIJO, A., SHLEVKOV, E. and MORATA, G. (2009). The role of Dpp and Wg in compensatory proliferation and in the formation of hyperplastic overgrowths caused by apoptotic cells in the Drosophila wing disc. Development. 136: 1169-77.

RHINER, C., LOPEZ-GAY, J.M., SOLDINI, D., CASAS-TINTO, S., MARTIN, F.A., LOMBARDIA, L. and MORENO, E. (2010). Flower forms an extracellular code that 


\section{G. Morata and L. Ballesteros-Arias}

reveals the fitness of a cell to its neighbors in Drosophila. Dev Cell 18: 985-998.

RHINER, C. and MORENO, E. (2009). Super competition as a possible mechanism to pioneer precancerous fields. Carcinogenesis 30: 723-728.

RODRIGUES, A.B., ZORANOVIC, T., AYALA-CAMARGO, A., GREWAL, S., REYESROBLES, T., KRASNY, M., WU, D.C., JOHNSTON, L.A. and BACH, E.A. (2012). Activated STAT regulates growth and induces competitive interactions independently of Myc, Yorkie, Wingless and ribosome biogenesis. Development 139: 4051-4061.

RYOO, H.D., GORENC, T. and STELLER, H. (2004). Apoptotic cells can induce compensatory cell proliferation through the JNK and the Wingless signaling pathways. Dev Cell 7: 491-501.

SAEBOE-LARSSEN, S., LYAMOURI, M., MERRIAM, J., OKSVOLD, M.P. and LAMBERTSSON, A. (1998). Ribosomal protein insufficiency and the minute syndrome in Drosophila: a dose-response relationship. Genetics 148: 1215-1224.

SANCHO, M., DI-GREGORIO, A., GEORGE, N., POZZI, S., SANCHEZ, J.M., PER NAUTE, B. and RODRIGUEZ, T.A. (2013). Competitive interactions eliminate unfit embryonic stem cells at the onset of differentiation. Dev Cell 26: 19-30.

SHIVAS, J.M., MORRISON, H.A., BILDER, D. and SKOP, A.R. (2010). Polarity and endocytosis: reciprocal regulation. Trends Cell Biol 20: 445-452.

SIMPSON, P. (1979). Parameters of cell competition in the comparments of the wing of Drosophila. Dev. Biol. 69: 182-193.

SIMPSON, P. and MORATA, G. (1981). Differential mitotic rates and patterns of growth in compartments in the Drosophila wing. Dev Biol 85: 299-308.
STRATTON, M.R., CAMPBELL, P.J. and FUTREAL, P.A. (2009). The cancer genome Nature 458: 719-724.

STRONACH, B.E. and PERRIMON, N. (1999). Stress signaling in Drosophila. Oncogene 18: 6172-6182.

TAMORI, Y., BIALUCHA, C.U., TIAN, A.G., KAJITA, M., HUANG, Y.C., NORMAN, M., HARRISON, N., POULTON, J., IVANOVITCH, K., DISCH, L. et al., (2010). Involvement of Lgl and Mahjong/VprBP in cell competition. PLoS Bio/8: 1000422.

TEPASS, U., TANENTZAPF, G., WARD, R. and FEHON, R. (2001). Epithelial cell polarity and cell junctions in Drosophila. Annu Rev Genet 35: 747-784.

TYLER, D.M., LI, W., ZHUO, N., PELLOCK, B. and BAKER, N.E. (2007). Genes affecting cell competition in Drosophila. Genetics 175: 643-657.

VINCENT, J.P., KOLAHGAR, G., GAGLIARDI, M. and PIDDINI, E. (2011). Steep differences in wingless signaling trigger Myc-independent competitive cell interactions. Dev Cell 21: 366-374.

YAO, C.K., LIN, Y.Q., LY, C.V., OHYAMA, T., HAUETER, C.M., MOISEENKOVA-BELL, V.Y., WENSEL, T.G. and BELLEN, H.J. (2009). A synaptic vesicle-associated $\mathrm{Ca} 2+$ channel promotes endocytosis and couples exocytosis to endocytosis. Cell 138: 947-960.

ZIOSI, M., BAENA-LOPEZ, L.A., GRIFONI, D., FROLDI, F., PESSION, A., GAROIA F., TROTTA, V., BELLOSTA, P. and CAVICCHI, S. (2010). dMyc functions downstream of Yorkie to promote the supercompetitive behavior of hippo pathway mutant cells. PLoS Genet 6: e1001140. 


\section{Further Related Reading, published previously in the Int. J. Dev. Biol.}

Revisiting DNA damage repair, p53-mediated apoptosis and cisplatin sensitivity in germ cell tumors

Francesca Cavallo, Darren R. Feldman and Marco Barchi

Int. J. Dev. Biol. (2013) 57: 273-280

Regulation of programmed cell death during neural induction in the chick embryo Anna Gibson, Neil Robinson, Andrea Streit, Guojun Sheng and Claudio D. Stern Int. J. Dev. Biol. (2011) 55: 33-43

Life-giving caspases: revealing new roles during mouse embryo preimplantation development

Dolores Busso, Calixto Dominguez, Tomas Perez-Acle and Ricardo D. Moreno Int. J. Dev. Biol. (2010) 54: 857-865

Both jnk and apoptosis pathways regulate growth and terminalia rotation during Drosophila genital disc development

Sergio Benitez, Claudia Sosa, Nicolás Tomasini and Ana Macías

Int. J. Dev. Biol. (2010) 54: 643-653

Apoptosis in Drosophila: compensatory proliferation and undead cells Francisco A. Martín, Ainhoa Peréz-Garijo and Ginés Morata Int. J. Dev. Biol. (2009) 53: 1341-1347

Key apoptosis regulating proteins are down-regulated during postnatal tissue development

Shane D. Madden, Maryanne Donovan and Thomas G. Cotter

Int. J. Dev. Biol. (2007) 51: 415-424

NMDA-receptor blockade enhances cell apoptosis in the developing retina of the postnatal rat

María Hernández, Inmaculada Guerrikagoitia, Luis Martínez-Millan and Elena Vecino Int. J. Dev. Biol. (2007) 51: 117-122

5 yr ISI Impact Factor $(2013)=2.879$
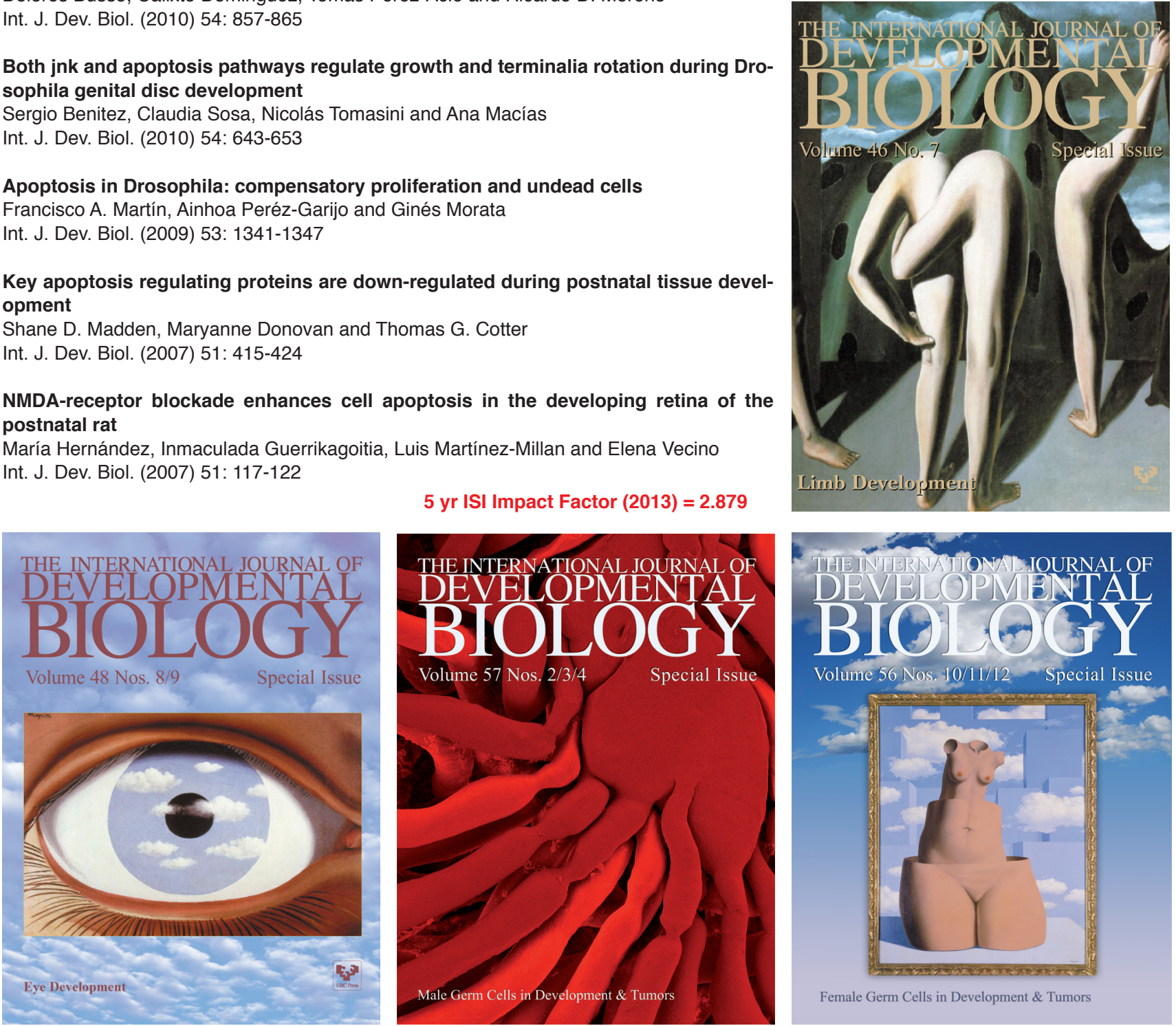

Volume 56 Nos. 10/11/12 - Special Issue

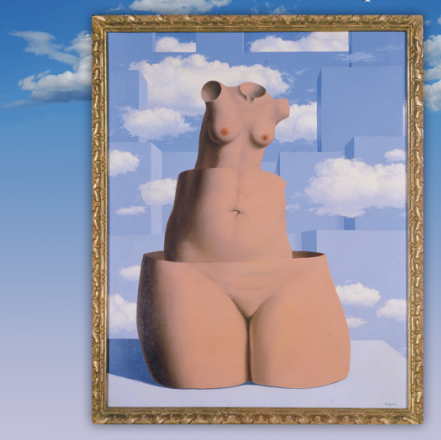

Female Germ Cells in Development \& Tumors 